\title{
Polystyrene microbeads modulate the energy metabolism of the marine diatom Chaetoceros neogracile
}

\author{
Seoane Marta 1, 2, ${ }^{*}$, González-Fernández Carmen ${ }^{2}$, Soudant Philippe ${ }^{2}$, Huvet Arnaud ${ }^{3}$, \\ Esperanza Marta ${ }^{1}$, Cid Ángeles ${ }^{1}$, Paul-Pont lka ${ }^{2}$
}

1 Laboratorio de Microbiología, Facultad de Ciencias, Universidade da Coruña, Campus da Zapateira s/n, 15071, A Coruña, Spain

2 Laboratoire des Sciences de l'Environnement Marin (LEMAR), UMR 6539 CNRS/UBO/IRD/IFREMER, Institut Universitaire Européen de la Mer (IUEM), Technopôle Brest-Iroise, Rue Dumont d'Urville, 29280, Plouzané, France

3 Ifremer, Laboratoire des Sciences de l'Environnement Marin (LEMAR, UMR 6539

CNRS/UBO/IRD/IFREMER), Centre Bretagne, CS 10070, 29280, Plouzané, France

* Corresponding author : Marta Seoane, email address : marta.seoane@udc.es

\begin{abstract}
:
Due to the growing concern about the presence of microplastics (MP) in the environment, the number of studies evaluating the toxicity of these small persistent particles on different marine species has increased in recent years. Few studies have addressed their impact on marine phytoplankton, a subject of great concern since they are primary producers of the aquatic food web. The aim of this study is to unravel the cytotoxicity of $2.5 \mu \mathrm{g} \mathrm{mL}-1$ unlabelled amino-modified polystyrene beads of different sizes $(0.5$ and $2 \mu \mathrm{m})$ on the marine diatom Chaetoceros neogracile. In addition to traditional growth and photosynthesis endpoints, several physiological and biochemical parameters were monitored every $24 \mathrm{~h}$ in C. neogracile cells by flow cytometry during their exponential growth $(72 \mathrm{~h})$. Dynamic Light Scattering measurements revealed the strong aggregation and the negative charge of the beads assayed in the culture medium, which seemed to minimize particle interaction with cells and potentially associated impacts. Indeed, MP were not attached to the microalgal cell wall, as evidenced by scanning electron micrographs. Cell growth, morphology, photosynthesis, reactive oxygen species levels and membrane potential remained unaltered. However, exposure to MP significantly decreased the cellular esterase activity and the neutral lipid content. Microalgal oil bodies could serve as an energy source for maintaining a healthy cellular status. Thus, MP-exposed cells modulate their energy metabolism to properly acclimate to the stress conditions.
\end{abstract}




\section{Graphical abstract}

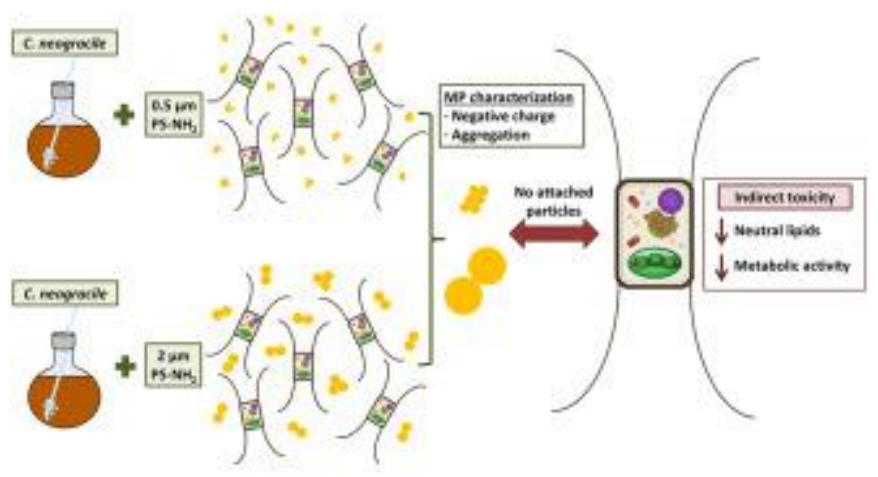

Graphical abstract

\section{Highlights}

- Effects of 0.5 and $2 \mu \mathrm{m}$ PS-NH 2 microplastics (MP) were evaluated on C. neogracile. MP showed negative charge, were aggregated and were not attached to the cell wall. Exposure to MP decreased the cellular metabolic activity and neutral lipid content. Cells modulate their energy metabolism to properly acclimate to the stress conditions. Microalgal oil bodies serve as an energy source for maintaining a healthy status.

Keywords : icroalgae, microplastic, flow cytometry, cytotoxicity, scanning electron microscopy. 


\section{Introduction}

Plastic wastes constitute a major portion of marine litter (Ruiz-Orejón, 2016). Synthetic polymers have excellent properties for many packaging applications and manufacturing processes that have led to their increasing use throughout the last decades, reaching an annual production of 335 million tons in 2016 (Plastics Europe, 2017). However, the characteristics that make plastics useful materials (low cost, high durability, low density) also make them a menace to the environment (Ryan, 2015). Plastics may persist in the environment for many years and can be easily dispersed by oceanic currents even to remote areas of the world, far away from the source of contamination (Barnes et al., 2009; Peeken et al., 2018; Pham et al., 2014; Ryan et al., 2009).

The concern of the scientific community about plastic pollution and its impacts on marine organisms has increased in recent years especially in regards with the high proportion of small persistent particles commonly called microplastics (MP) (Andrady, 2015). MP are defined as plastic particles with a size smaller than $5 \mathrm{~mm}$ (NOAA, 2008). Lately, a new category of plastic debris, named nanoplastics (NP), was described as particles <100 nm (Galloway et al., 2017) or $<1 \mu \mathrm{m}$ (Gigault et al., 2018). In this study, we will keep the NP definition as particles $<100 \mathrm{~nm}$ and therefore, considering MP as particles from $100 \mathrm{~nm}$ to $5 \mathrm{~mm}$ in size. Both MP and NP may originate from the fragmentation of larger plastic debris (e.g., bags, bottles and fishing nets) in the marine environment caused by a combination of physical and chemical processes such as mechanical abrasion, photochemical and thermo-oxidation, hydrolysis or even biological degradation (Dawson et al., 2018; Gigault et al., 2016; Lambert and Wagner; 2016). In addition, MP could also reach the aquatic environment directly since many products used plastics at the micrometric size (e.g., personal care and household cleaning products or microfibers from synthetic clothing) (Andrady, 2015), while the increased use of NP in diverse industries (cosmetics, drugs, lubricants) may lead to their release in the environment (Hernandez et al., 2017; Lusher et al., 2017). MP have been found to be ubiquitously present in all environmental compartments of the aquatic environment, from surface waters and water column to deep-sea sediments (Reviewed in Paul-Pont et al., 2018). In reference to object counts, MP constitute more than $92 \%$ of floating plastics in the oceans (Cole et al., 2011; Eriksen et al., 2014). Regarding reported environmental concentrations, some of the highest have been detected in the southern North Sea reaching 1,700,000 items $\mathrm{m}^{-3}\left(\sim 8.5 \mathrm{mg} \mathrm{L}^{-1}\right)$ for plastic particles $>80$ $\mu \mathrm{m}$ (Dubaish and Liebezeit, 2013). However, due to the unavailability of methods, there are no field determinations of MP as small as those used in most experimental studies $(<20 \mu \mathrm{m}$; Filella, 2015). For nanoplastics, no quantitative data exists in situ and only indirect evidence of their presence has been debated recently (Ter Halle et al., 2017). 
Exposure laboratory experiments do not reflect the complexity of the marine environment; however, they may contribute to disclose and aware of the effect of plastics debris on marine organisms (Paul-Pont et al., 2018; Phuong et al., 2016). Several studies have investigated how MP can be ingested by aquatic animals leading to negative consequences for them and for the aquatic food chain (Yokota et al., 2017). Nevertheless, there is still a scarcity of knowledge about the impacts of MP on phytoplankton, which constitutes the basis of the aquatic food webs. In particular, diatoms are considered one of the most diverse and ecologically important phytoplanktonic groups and are responsible for approximately $20 \%$ of the overall primary production on Earth, playing a central role in the biogeochemical cycling of important nutrients (Malviya et al., 2016; Rosenwasser et al., 2014).

The aim of this study was to assess the potential effects of two different sizes $(0.5 \mu \mathrm{m}$ and 2 $\mu \mathrm{m}$ ) of unlabelled polystyrene (PS) beads on the marine diatom Chaetoceros neogracile, trying to disclose differential impacts depending on particle size, as smaller particles are expected to be more toxic (Sjollema et a., 2016). To perform the experiments, PS beads with amino $\left(-\mathrm{NH}_{2}\right)$ surface modifications were used at $2.5 \mathrm{\mu g} \mathrm{mL}^{-1}$, concentration set to compare with the $72 \mathrm{~h}$ $\mathrm{EC}_{50}$ value of $50 \mathrm{~nm}$ PS-NH $\mathrm{NP}_{2} \mathrm{NP}$ (data not shown). PS is one of the most used plastics worldwide and it is one of the plastic polymers type most frequently detected as micro-debris in marine environments (Andrady, 2011). PS- $\mathrm{NH}_{2}$ beads have been amply used as model particles in ecotoxicology and have been shown to cause severe damages on different organisms of the aquatic trophic chain (Bergami et al., 2017; Bhattacharya et al., 2010; Canesi et al., 2017; Manfra et al., 2017; Marques-Santos et al., 2018; Pinsino et al., 2017; Tallec et al., 2018). Particle behaviour was measured in Milli-Q water, seawater and in the culture medium using Dynamic Light Scattering (DLS) to assess potential particle aggregation or changes in the particle surface charge. To assess PS- $\mathrm{NH}_{2}$ MP effects on $\mathrm{C}$. neogracile several physiological and biochemical parameters such as cell morphology, autofluorescence, esterase activity, reactive oxygen species (ROS) levels, cytoplasmic membrane potential and neutral lipid content were monitored by flow cytometry (FCM) in addition to traditional growth and photosynthesis endpoints. Furthermore, potential structural damages and disposition or adsorption of unlabelled PS- $\mathrm{NH}_{2}$ beads on microalgal surface were determined using scanning electron microscopy (SEM).

\section{Materials and methods}

\subsection{Microalgal cultures}

Chaetoceros neogracile (Bacillariophyceae) was obtained from the Culture Collection of Algae and Protozoa of the Scottish Marine Institute (strain CCAP 1010-3). C. neogracile is a nonmotile centric marine diatom (width $=4 \mu \mathrm{m}$, length $=7 \mu \mathrm{m}$ ) encased in lightly siliceous valves 
114 (frustules), covered with an organic coating (Hecky et al., 1973). This species was selected

115 based on its predominance in marine phytoplankton communities (Malviya et al., 2016). Stock microalgal cultures were maintained in filtered (pore size: $0.2 \mu \mathrm{m}$ ) and autoclaved natural seawater (FSW) supplied with $1 \mathrm{~mL} \mathrm{~L}^{-1}$ of Conway medium (Walne, 1966) and enriched with silica $\left(\mathrm{Na}_{2} \mathrm{SiO}_{3} \cdot 9 \mathrm{H}_{2} \mathrm{O}\right)\left(1.0710^{-4} \mathrm{M}\right)$. Flasks were kept at $20{ }^{\circ} \mathrm{C}$, with continuous aeration and light at $100 \mu \mathrm{mol}$ photon $\mathrm{m}^{-2} \mathrm{~s}^{-1} . \mathrm{CO}_{2}$ was supplied to keep the $\mathrm{pH}$ between 7.5 and 7.9.

\subsection{Particle characterization}

Unlabelled $0.5 \mu \mathrm{m}$ and $2 \mu \mathrm{m}$ PS- $\mathrm{NH}_{2}$ particles were purchased from Micromod (Micromod Partikeltechnologie $\mathrm{GmbH}$ ). Both particles were characterized by Dynamic Light Scattering (DLS) using Zetasizer Nano Series ZS (Malvern instruments) as conducted by Tallec et al. (2018). Size (Z-average in $\mathrm{nm}$ ), charge ( $\zeta$-potential in $\mathrm{mV}$ ) and aggregation state (Polydispersity Index, Pdl in arbitrary units (a.u.)) were measured in Milli-Q water, FSW and also in filtered (0.2 $\mu \mathrm{m})$ microalgal culture medium. When Pdl exceeds 0.2 a.u. particles were considered to be aggregated. Measurements were carried out in triplicate, each containing 13 runs of $10 \mathrm{~s}$ for Zaverage and 20 runs, $3 \mathrm{~s}$ delay for $\zeta$-potential following the protocol described in Della Torre et al. (2014). Data were analyzed using Zetasizer Nano Series software, version 6.20.

\subsection{Microalgal exposure to microplastics}

Microalgae cells were exposed to both particles in different batch cultures for $72 \mathrm{~h}$, during the exponential growth phase, as recommended in most standardized growth inhibition tests with microalgae (OECD 201, 2011). It has also been shown that during exponential growth phase MP impaired more drastically the major cellular and physiological parameters (Mao et al., 2018). Exposures were performed in triplicates in $500 \mathrm{~mL}$ glassware balloon flasks filled with $300 \mathrm{~mL}$ of microalgal culture under the same environmental conditions as stock cultures. Microalgal cells in early exponential growth phase were used as inoculum and initial cell density was adjusted to $4 \times 10^{5}$ cells $\mathrm{mL}^{-1}$. The $\mathrm{MP}$ concentration used $\left(2.5 \mu \mathrm{g} \mathrm{mL}^{-1}\right.$ ) corresponds to the $72 \mathrm{~h} \mathrm{EC}_{50}$ value of $50 \mathrm{~nm}$ PS- $\mathrm{NH}_{2} \mathrm{NP}$ (data not shown) and was established to compare results with other laboratory studies (Long et al., 2017; Mao et al., 2018; Zhang et al., 2017), but not as high as in most published works, so that we could get closer to worst environmental scenarios (Paul-Pont et al., 2018). This same mass concentration for the two beads tested results in differences in the nominal concentration in number of particles per $\mathrm{mL}$, corresponding to $3.7 \times 10^{7}$ particles $\mathrm{mL}^{-1}$ for the $0.5 \mu \mathrm{m} \mathrm{MP}$ and to $5.7 \times 10^{5}$ particles $\mathrm{mL}^{-1}$ for the $2 \mu \mathrm{m}$ MP. Before the experiment, MP stock solutions were diluted in Milli-Q water. The volume of the diluted MP solutions added to microalgal cultures to reach the final MP concentration used for the assay $\left(2.5 \mu \mathrm{g} \mathrm{mL}^{-1}\right)$ never exceeded $0.3 \%$ of the final culture volume. Therefore, in the whole process an approximate dilution of $1 / 20000$ of the 
commercial MP stock was made. Analyses were performed in fresh samples every $24 \mathrm{~h}$ during the $72 \mathrm{~h}$ of the test. Additionally, after $48 \mathrm{~h}$ of exposure, halfway in the experiment, control and exposed samples were fixed for microscopy observations.

\subsection{Scanning electron microscopy}

Samples of control and MP exposed cultures were diluted to $10^{5}$ cells $\mathrm{mL}^{-1}$ and fixed in $6 \%$ glutaraldehyde in $0.1 \mathrm{M}$ sodium cacodylate buffer (1.75\% w/v of $\mathrm{NaCl}, \mathrm{pH} 7.2$ ). Suspensions were incubated for 2 hours at $4{ }^{\circ} \mathrm{C}$ before being filtered through polycarbonate filters (Nucleopore PC) with a $2 \mu \mathrm{m}$ pore size. Then, samples were prepared for scanning electron microscopy (SEM) observation following the method previously described by Foulon et al. (2016). Finally, samples were observed with a Hitachi S-3200N microscope.

\subsection{Flow cytometric analyses}

Flow cytometric (FCM) analyses were performed using an Easy-Cyte Plus 6HT flow cytometer (Guava Merck Millipore ${ }^{\circledR}$ ) equipped with a $488 \mathrm{~nm}$ argon excitation laser, detectors of forward (FSC) and side (SSC) light scatter and three fluorescence detectors: green ( $525 \mathrm{~nm} \pm 15)$, yellow $(583 \mathrm{~nm} \pm 13)$ and red $(680 \mathrm{~nm} \pm 15)$. All fluorescence measurements were obtained in a logarithmic scale and data were computed as the mean fluorescence value of the cell population in arbitrary units (a.u.). Collected data from the FCM were analyzed with the software InCyte (Millipore).

\subsubsection{Cellular density and growth rate}

Direct absolute cell counts were carried out daily by FCM to determine the cellular density of control and treated cultures. Growth rates $(\mu)$ were also calculated as described in Seoane et al. (2017a).

\subsubsection{Morphological parameters and chlorophyll $a$ fluorescence}

Forward light scatter (FSC) and side light scatter (SSC) values were measured and used as estimates of morphological changes. Natural red autofluorescence, related to chlorophyll $a$ content, was also analysed.

\subsubsection{Esterase activity}

Esterase activity in C. neogracile cells was studied using the fluorescein diacetate (FDA) cytometric assay previously described in Seoane et al. (2017b). Cells were incubated with FDA at a final concentration of $6 \mu \mathrm{M}$ for $10 \mathrm{~min}$ at room temperature in the dark. FDA is a nonfluorescent, non-polar lipophilic molecule that diffuses across cell membranes. After entering the cell, its acetate residues are cleaved off by non-specific esterases and the polar hydrophilic fluorescent product fluorescein is retained by cells with intact plasma membranes. Since fluorescein is accumulated by viable and active cells, esterase activity is measured by means of the green fluorescent intensity emitted (Prado et al., 2009). 


\subsubsection{Oxidative stress: intracellular levels of reactive oxygen species} Reactive oxygen species (ROS) content was measured using 2,7-dichlorofluorescein diacetate (DCFH-DA) as described in González-Fernández et al. (2018). The cells of $C$. neogracile were incubated with DCFH-DA at a final concentration of $10 \mu \mathrm{M}$ for $50 \mathrm{~min}$ at room temperature in the dark. DCFH-DA is a cell-permeable non-florescent probe that is hydrolysed (de-esterified) intracellularly to form the highly green fluorescent DCF upon oxidation with ROS. Thus, the green fluorescence measured is quantitatively related to the ROS content in cells.

\subsubsection{Cytoplasmic membrane potential}

Potential changes in cytoplasmic membrane potential were determined using the bis-(1,3dibutylbarbituric acid) trimethine oxonol $\left(\operatorname{DiBAC}_{4}(3)\right)$ following the protocol previously described by Seoane et al. (2017a). Cells were incubated with $\operatorname{DiBAC}_{4}(3)$ at a final concentration of $2 \mu \mathrm{M}$ for $10 \mathrm{~min}$ at room temperature in the dark. $\operatorname{DiBAC}_{4}(3)$ can enter depolarized cells where it binds to intracellular proteins or membranes showing green fluorescent emission (Wolff et al., 2003).

\subsubsection{Neutral lipid content}

Neutral lipid content was assessed using the specific lipid droplet stain BODIPY 493/503. This highly lipophilic neutral dye easily goes through cell and organelle membranes and accumulates in intracellular oil-containing organelles, known as lipid bodies, showing green fluorescence. BODIPY has proven to be very effective for lipid measurement in microalgae (Govender et al., 2012; Rumin et al., 2015). Cells of $C$. neogracile were incubated with BODIPY $493 / 503$ at a final concentration of $10 \mu \mathrm{M}$ for $10 \mathrm{~min}$ at room temperature in the dark.

\subsection{Photosynthetic efficiency}

The effective quantum yield (QY) of photochemical energy conversion in photosystem II (PSII) was measured by Pulse Amplitude Modulation (PAM) fluorometry using an AquaPen-C APC 100 fluorometer (Photon Systems Instruments, Czech Republic) equipped with a blue (455 nm) LED excitation light. Aliquots of each culture were dark-adapted for 30 minutes before measurements.

\subsection{Statistical analysis of results}

Statistical analysis was performed using IBM SPSS Statistics software 21.0. Mean fluorescence values and standard deviation (SD) of the three biological replicates were determined for exposed and control cultures. Data were checked for normal distribution (Shapiro-Wilk test) and homogeneity of variance (Levene test). One-way analysis of variance (ANOVA) was performed to test for differences among treatments at each sampling time. When significant differences were observed, multiple comparisons among treatments were made using the Tukey's post hoc test. For DLS data, pairwise comparisons were also made to compare particle 
219 behaviour (size and charge) between the three media (Supp. Table 1). A $p$-value $<0.05$ was

220 considered statistically significant for all the analyses.

\section{3. Results and discussion}

\section{3.1. Particle characterization: actual size, charge and aggregation}

DLS analysis of the MP suspended in Milli-Q water confirmed the approximate size indicated by the commercial supplier for the two particle sizes used, with Z-averages of $602.5 \pm 27.3$ and $2274.0 \pm 100.9 \mathrm{~nm}$, which correspond to the nominal sizes of $0.5 \mu \mathrm{m}$ and $2 \mu \mathrm{m}$, respectively (Table 1). Data also showed an optimal dispersion and stability in Milli-Q water since aggregation was negligible for both particles, as suggested by a $\mathrm{Pdl}<0.2$ (Table 1). However, plastic particles showed a significant increase in Z-average reaching values of $2899.0 \pm 96.0 \mathrm{~nm}$ and $5932.0 \pm 694.4 \mathrm{~nm}$ when suspended in FSW and values of $3268.0 \pm 64.3 \mathrm{~nm}$ and $4342.3 \pm$ $294.2 \mathrm{~nm}$ in microalgae medium for $0.5 \mu \mathrm{m}$ and $2 \mu \mathrm{m}$ PS-NH $\mathrm{NH}_{2}$ beads, respectively (Table 1; Supp. Table 1). These data indicated an increase in particle size congruent with the observed Pdl values (>0.2) that indicated aggregation (Table 1 ). three media assayed (Table 1) although a positive charge was expected since the beads used presented amino surface modifications. Therefore, particle characteristics must be assessed prior to performing laboratory exposure to properly interpret particle behaviour and toxicity. Such difference of charge has also been reported by Sun et al. (2018) with $1 \mu \mathrm{m}$ PS-NH $\mathrm{NH}_{2}$ beads and by González-Fernández et al. (2018) and Lundqvist et al. (2008) with 100 nm PS-NH $\mathrm{NP}_{2}$. These discrepancies may derivate from the manufacturing process which may change according to the commercial suppliers. More information and measurements regarding physico-chemical properties of MP is thus a prerequisite for a better interpretation of their behaviour and biological impact in different solutions (González-Fernández et al., 2018). Significant lower absolute values of $\zeta$-potential (closer to zero) were obtained for both particles in FSW and in the culture medium as compared to the values in Milli-Q water (Table 1; Supp. Table 1). These results are in accordance with the results of size and particle aggregation obtained. The $\zeta$-potential is a key indicator of the stability of colloidal dispersions. The magnitude of this value indicates the degree of electrostatic repulsion between particles. Particle solutions with high $\zeta$-potential (negative or positive) are more stable and greatly dispersed, while particles with a $\zeta$-potential between -10 and $+10 \mathrm{mV}$ are less stable and tend to aggregate. The high concentration of $\mathrm{NaCl}$ and other ions in $\mathrm{FSW}$ as well as the presence of proteins or other natural organic matter in the filtered microalgae medium are likely interacting with the particle surface group eliminating the repulsion forces that maintain particles isolated and promoting aggregation (Canesi et al., 2017; Paul-Pont et al., 2018). These 
254 surface interactions can explain particle behaviour changes (surface charge, size and

255 aggregation state) observed in FSW and filtered microalgae medium as compared to particles

256 in Milli-Q water (Supp. Table 1). In environmental media, surface charge neutralization and

257 increases in particle size are often observed, due to the formation of a protein coating (called 258 ecocorona; Galloway et al., 2017) on the particle surface (Marques-Santos et al., 2018). 259 Therefore, the medium and related parameters should be always taken into account for 260 particle characterization (Della Torre et al., 2014).

\section{3.2. Scanning electron microscopy observations}

262 Micrographs of $C$. neogracile cells exposed to both MP sizes were presented, evidencing intact 263 frustules, similar to control cells, without MP attached at the surface cell (Fig. 1A, B, C). Most cells showed broken setae, located close to the cell, likely because of the force exerted during the filtration process required for sample preparation for SEM observation. Several studies showed the adsorption of plastic micro and nanoparticles onto the microalgal cell surface (Bhattacharya et al., 2010; Mao et al., 2018) and this adhesion was found to be stronger with positively charged NP than with the negatively charged ones (Bergami et al., 2017; Nolte et al., 2017). The observed increase in MP aggregates and the change in MP charge (Table 1) could impacts. However, it cannot be excluded that a previous interaction between MP and microalgae occurred. Although the beads tested showed negative charges, MP could be adsorbed on microalgae by weak chemical bonds and SEM preparation could have detached them from the cell wall. Nevertheless, Long et al. (2017) showed that aggregation between $C$. neogracile cells and $2 \mu \mathrm{m}$ uncharged PS MP is rare during exponential growth (about 2\%) and mainly occurred during the stationary growth phase $(<20 \%)$.

Micrographs also evidenced free small MP aggregates and bacteria attached to the filter and/or associated to MP aggregates (Fig. 1D, E, F). Bacteria could interact with plastic particles and colonize them, as it has been shown by Foulon et al. (2016) with $5 \mu \mathrm{m}$ PS MP. Accordingly, bacteria concentration during the experiment was measured by flow cytometry and no significant differences were found among control and exposed cultures (Supp. Table 2).

\subsection{Little effect of MP exposure on cell growth}

Only a slight but significant decrease in growth rate was detected in cultures exposed to $2 \mu \mathrm{m}$ MP for $72 h\left(\right.$ ANOVA; $\left.F_{(2,6)}=13.25 ; p<0.01\right)$ (Table 2). The strong aggregation pattern of the MP in the microalgal medium observed in this study (Table 1) could reduce their bioavailability and explain their limited impact on growth, as previously hypothesized in other studies with PS particles (Bergami et al., 2017; Della Torre et al., 2014; Gambardella et al., 2018). Previous studies that tested different MP concentrations of similar size range, reported no effect on the 
growth of microalgae. Long et al. (2017) did not observe adverse effects on the growth and chlorophyll fluorescence of $C$. neogracile cells exposed to $0.04 \mu \mathrm{g} \mathrm{m}^{-1}$ of uncharged $2 \mu \mathrm{m}$ PS MP. Davarpanah and Guilhermino (2015) did not found significant effects on the growth of the marine green microalgae Tetraselmis chuii exposed for $96 \mathrm{~h}$ to concentrations ranging from 0.046 to $1.472 \mu \mathrm{g} \mathrm{mL}^{-1}$ of red fluorescent polyethylene microspheres (1-5 $\mu \mathrm{m}$ diameter). Sjollema et al. (2016) analyzed the growth and photosynthetic capacity of the marine green microalgae Dunaliella tertiolecta exposed to three sizes ( $50 \mathrm{~nm}, 0.5$ and $6 \mu \mathrm{m}$ ) of uncharged PS beads and also observed that these beads had negligible effects on microalgae growth, except for nano-sized particles $(50 \mathrm{~nm})$ at high exposure concentrations $\left(250 \mathrm{\mu g} \mathrm{mL}^{-1}\right)$, suggesting that the effect on microalgal growth increases with decreasing bead size.

Deleterious effects of MP on microalgal growth were only detected at very high concentrations, even higher than the concentration used in this study $\left(2.5 \mu \mathrm{g} \mathrm{mL}^{-1}\right)$. However, influence of particle size was rarely considered and controlled which are making comparisons difficult. Mao et al. (2018) showed that 10,50 and $100 \mu \mathrm{g} \mathrm{mL}^{-1}$ of 0.1 and $1 \mu \mathrm{m}$ PS MP caused a dose-dependent negative effect on the growth and photosynthetic activity of the freshwater green microalgae Chlorella pyrenoidosa during its logarithmic growth phase. The mechanism associated to the toxicity was attributed to the physical damage and oxidative stress. Gambardella et al. (2018) exposed the marine microalgae D. tertiolecta to a wide range of $0.1 \mu \mathrm{m}$ PS MP concentrations (0.001-0.01-0.1-1-10 $\left.\mathrm{g} \mathrm{m} \mathrm{m}^{-1}\right)$ for $72 \mathrm{~h}$ and also observed a dosedependent growth inhibition. At the highest MP concentration they tested $\left(10 \mu \mathrm{gL}^{-1}\right)$ about $40 \%$ of growth inhibition was observed. Authors suggested that this growth inhibition was due to the fact that microalgae energy sources were used in detoxification processes, such as the generation of extracellular polysaccharides. It is also noteworthy that most of the published works assessing the effects of MP on phytoplankton were made with green microalgae, and scarce data about the effects of the small MP fraction on other phytoplankton taxonomic groups is available.

\subsection{MP did not cause significant alterations of cell morphology and photosynthesis-related} parameters

Potential changes in the structural properties of the diatom $C$. neogracile exposed to the MP were studied by FCM based on light diffraction. Neither of the two particle sizes significantly altered the morphology of microalgal cells, since no changes were detected in the FSC and SSC signals (Supp. Table 3). Similarly, Long et al. (2017) did not observed FSC and SSC changes in C. neogracile cells exposed to $0.04 \mu \mathrm{g} \mathrm{mL}^{-1}$ of uncharged $2 \mu \mathrm{m}$ PS MP for all duration of culture growth. The fact that 0.5 and $2 \mu \mathrm{m}$ PS- $\mathrm{NH}_{2} \mathrm{MP}$ aggregate and become negatively charged may have affected the effectiveness of physical adsorption of these MP onto the cell wall. 
Environmental stressors could affect the function of photosynthetic systems, thereby affecting the fluorescence emission (Geoffroy et al., 2007; Juneau et al., 2002). Natural red autofluorescence measured by FCM and effective quantum yield (QY) measured by PAM in $C$. neogracile cells did not show significant changes upon exposure to $2.5 \mu \mathrm{g} \mathrm{m}^{-1}$ of 0.5 and $2 \mu \mathrm{m}$ PS-NH $\mathrm{N}_{2}$ MP as compared to control condition (Supp. Table 3). Mao et al. (2018) showed that upon exposure of $0.1 \mu \mathrm{m}$ and $1 \mu \mathrm{m}$ PS MP at $10 \mu \mathrm{g} \mathrm{mL}^{-1}$, adsorption of MP onto the surface of the freshwater microalgae Chlorella pyrenoidosa during its exponential growth phase could provoke shading effects, hindering algal photosynthesis. However, this phenomenon appears to be negligible for the particles tested, as shown in SEM micrographs, probably due to the electrostatic repulsion exerted by its observed negative charge on microalgal cell membrane (Table 1).

\subsection{Decrease in esterase activity as an early response to MP exposure}

A significant decrease in esterase activity of $C$. neogracile cells exposed to the MP tested with respect to control cells was observed after $24 \mathrm{~h}\left(\right.$ ANOVA; $\left.F_{(2,6)}=7.07 ; p<0.05\right)$ and $48 \mathrm{~h}$ (ANOVA; $F_{(2,6)}=4.96 ; p<0.05$ ) (Fig. $2 A$ ). This reduction was more pronounced after $24 \mathrm{~h}$ of exposure, followed by a slight recovery at $48 \mathrm{~h}$. After $72 \mathrm{~h}$, esterase activity appeared fully recovered as significant differences were not observed anymore among treatments (ANOVA; $\left.F_{(2,6)}=1.35 ; p>0.05\right)$ (Fig. 2A). Recovery from the detrimental effects caused by MP on microalgae was also observed by Mao et al. (2018) when cultures started the stationary phase. Representative flow cytometric histograms showing shifts in the green fluorescence intensity related to the esterase activity of $C$. neogracile cells in control cultures and cultures exposed to both MP are shown in Supp. Fig. 1.

The lack of effects on key parameters such as growth, morphology or photosynthesis was explained due to the absence of physical adsorption of MP onto diatom's cell wall. However, the decrease in esterase activity observed could be attributed to the contact between the MP and the microalgae during the culture. Contact, even temporal, could be detected and considered as a stress by the cells and may be translated into biochemical signals, triggering a response to deal with. It could be described as the "billiard ball effect". As documented in humans, cells may sense mechanical cues, although the details underlying how cells respond to mechanical forces are not well understood yet (Yusko et al., 2014). The potential release of chemicals from MP could be another explanation to the indirect toxicity detected. Monomers and/or additives incorporated during manufacture could be toxic to microalgae and could interfere with biological processes, explaining the decrease observed in the general metabolic activity of cells (Fig. 2A). Many exposure experiments reported significant toxicity of plastic leachates on aquatic organisms (reviewed in Hermabessiere et al., 2017). Virgin MP, frequently 
used as model materials in aquatic toxicity laboratory studies, are supposed to be free of additives or residual monomers. However, some studies suggest that commercial virgin plastic pellets may also leach toxic unknown chemicals (Nobre et al., 2015). Martínez-Gómez et al. (2017) reported significant toxicity of virgin and aged PS MP on the fertilization and larval development of sea urchins, and plastic leachates were found to have higher toxicity than the virgin and aged materials themselves. Toxicity of leachates from plastic products obtained after $72 \mathrm{~h}$ of leaching was also observed in the copepod Nitocra spinipes (Bejgarn et al., 2015). Moreover, it cannot be excluded the potential repercussions that amino functional groups could have on cells. MP are coated with $-\mathrm{NH}_{2}$ groups by chemical bonds and during laboratory exposure, light or other environmental factors could lead to bond cleavage.

As compared to the other parameters analysed, the FDA assay appeared more sensitive to detect physiological changes in cells exposed to these 0.5 and $2 \mu \mathrm{m}$ (nominal sizes) particles after a short period of time. Esterases involved in the FDA assay turn over on a time frame of several hours (Jochem, 2000). Therefore, this technique seems appropriate to detect changes in metabolic activity on a day-to-day or even shorter basis, which makes it well suited to monitor short-term phytoplankton responses to environmental changes or to diverse pollutants (Esperanza et al., 2015; Franklin et al., 2001; Prado et al., 2009; Seoane et al., 2017a; Seoane et al., 2017b). Our results showed that, with more subtle measurements, we can detect the impact of MP. This brings out the suitability and sensitivity of this assay with the flow cytometry technique to assess the effects of plastic debris on marine phytoplankton.

\subsection{Unaltered ROS production and membrane potential during MP exposure}

Microalgae may have higher levels of ROS as a result of changes in environmental conditions or the presence of contaminants. When there is an imbalance between the production of ROS and the cellular antioxidant defence mechanisms, oxidative stress increases leading to several cellular damages. In the present study, ROS production in C. neogracile cells was not significantly affected by the presence of MP in the medium (Supp. Table 4). ROS overproduction has been previously observed by Mao et al. (2018) during the exponential growth phase of the freshwater microalgae Chlorella pyrenoidosa exposed to $0.1 \mu \mathrm{m}$ and $1 \mu \mathrm{m}$ PS particles at very high concentrations $\left(10,50\right.$ and $\left.100 \mu \mathrm{gL}^{-1}\right)$. However, it seems that with the $0.5 \mu \mathrm{m}$ and $2 \mu \mathrm{m} \mathrm{MP}$ we tested (nominal sizes), the concentration used $\left(2.5 \mu \mathrm{g} \mathrm{mL}^{-1}\right.$ ) was not high enough to alter the intracellular equilibrium of $C$. neogracile ROS levels.

Regarding cytoplasmic membrane potential, no significant alterations were observed in cells exposed to MP (Supp. Table 4). Interactions between MP and biological membranes are driven by particle size, since small particles are suspected to interact more with biological membranes (Nel et al., 2006; Verma and Stellacci, 2010), and by particle surface properties, notably the net 
surface charge (Nolte et al., 2017). Taking into consideration the particle size, internalization of MP used $(0.5$ and $2 \mu \mathrm{m})$ was discarded on intact cells. Algal cell walls are semipermeable and the diameter of their pores determines its sieving properties (Navarro et al., 2008). Diatoms' wall pores are typically between 3 and $50 \mathrm{~nm}$ (Sanka et al., 2017). As long as there are no holes in the cell wall or loss of viability, only particles with a size smaller than that of the largest pore are expected to pass through the cell wall. Thus, the algal cell wall pore size is too small to transport MP used through the cell. Gambardella et al. (2018) evaluated MP internalization in the green microalgae $D$. tertiolecta using $0.1 \mu \mathrm{m}$ fluorescent PS MP. Although MP caused algal growth inhibition, they also discard MP internalization into cells, since all fluorescence beads were observed as aggregates in the medium, out of the microalgal cell surface. With regard to the charge, it is possibly related to differences in effectiveness of physical adsorption onto the cell wall, since cationic particles interact with membranes more easily than anionic ones (Bhattacharya et al., 2010; Nel et al., 2009). In the present study, the aggregation of MP and the negative charge measured seems to minimize MP effects. MP concentration and time exposure are also important factors for MP impacts. Mao et al. (2018) showed membrane damages such as cell wall thickening and loss of viability in C. pyrenoidosa exposed to PS MP at the higher concentration they tested $\left(100 \mu \mathrm{g} \mathrm{m}^{-1}\right)$ in long-term exposure (30 days). However, at the concentration used in our short-term study, we did not observed effects on membrane potential.

\subsection{Diminished neutral lipid content in MP-exposed cells}

Exposure to 0.5 and $2 \mu \mathrm{m}$ PS- $\mathrm{NH}_{2} \mathrm{MP}$ resulted in a significant decrease in the cellular neutral lipid content with respect to control cells at all tested times (ANOVA $24 h ; F_{(2,6)}=37.50$; $p<0.001$ ) (ANOVA $48 h ; F_{(2,6)}=12.08 ; p<0.01$ ) (ANOVA $72 h ; F_{(2,6)}=18.46 ; p<0.01$ ) (Fig. 2B). After $72 \mathrm{~h}$, the lipid content of MP-exposed cells was reduced by half with respect to control. Representative flow cytometric histograms showing shifts in the green fluorescence intensity related to the neutral lipid content of $C$. neogracile cells in control cultures and cultures exposed to both MP are shown in Supp. Fig. 2.

Microalgae generally accumulate neutral lipids, mainly triacylglycerol (TAG), in specific organelles called lipid bodies, upon stresses such as nutrient limitation, elevated temperatures, unfavourable light intensities, alkaline $\mathrm{pH}$, high salinity or dehydration (Zienkiewicz et al. 2016). In laboratory cultures, microalgae begin to accumulate lipids in the stationary phase of growth, when shortage of nutrients arrives (Huerlimann et al., 2010; Xu et al., 2008). Previous studies found disturbances in lipid metabolism after exposure to MP in other species such as marine fishes and mussels (Von Moos et al., 2012; Yin et al., 2018). Although exposure to MP does not usually cause mortality in marine organisms, it has been 
observed that it can affect them by altering their feeding behaviour and reducing their energy reserves, with consequences for growth and reproduction (Galloway et al., 2017). Microalgal oil bodies have a dynamic nature and appear to function as transient reservoirs, as the storage lipids are quick catabolized in response to environmental changes (Maeda et al., 2017). In the present study, oxidative stress was not detected in MP-exposed cells; therefore, the decrease in lipids observed cannot be associated with its oxidation, but to modulation of energy metabolism to properly acclimate to the stress conditions, maintaining a healthy status. As discussed previously, despite not having observed MP attached to the cell surface it cannot be excluded an interaction between MP and microalgae and an indirect toxicity due to i) the contact between MP and cells during the culture and ii) the potential toxic compounds (monomers, oligomers, additives or other chemicals) that could be leached from MP. The "consumption" of lipid reserves could be interpreted as a cell response to overcome the stress provoked by MP exposure and for the maintenance of the normal growth, photosynthesis and even the membrane integrity. Thus, microalgal oil bodies could serve as an energy source for their recovery. This decrease in the lipid content could also have ecological implications for food web trophic functioning by reducing microalgae nutritional quality for primary consumers and onward.

\section{Conclusions}

MP aggregated in FSW and in filtered culture medium, producing secondary particles with different properties, which make difficult assessing influence of size on MP toxicity. In addition, their $\zeta$-potential in FSW and in the culture medium outlined low negative values, fact that could have influenced their aggregation state and their interaction with the cell surface. It highlights the necessity to characterize behaviour of plastic particles in assay media before exposure to avoid bias in results interpretation.

Direct toxicity on key parameters such as cell growth, morphology, photosynthesis, ROS content and membrane potential was not observed and SEM micrographs showed that MP were not attached to the microalgal cell wall. However, indirect toxicity was detected because we unravelled a significant decrease in the esterase activity and the lipid reserves of MPexposed cells. Results suggest that microalgal oil bodies could serve as an energy source for the maintenance of the normal cellular growth, photosynthesis and membrane integrity to overcome the stress produced by MP exposure.

\section{Acknowledgements}

This work was supported by the ANR CESA (ANR-15-CE34-0006-02, NANOPLASTICS project) and by the Unique Inter-ministerial Fund (FUI) as part of the MICROPLASTIC2 project. 
M.S. acknowledges a pre-doctoral grant from "Campus do Mar" and all the LEMAR team for their help during the course of this project.

Authors would thank Philippe Miner for his help with microalgal cultures at the Ifremer facilities. We are also very grateful to Philippe Eliès from the PIMM core and to Olivier Lozach from the COSM team at the University of Western Brittany for the scanning electron microscopy observations and for providing us the equipment for DLS measurements, respectively.

\section{References}

Andrady, A.L., 2011. Microplastics in the marine environment. Mar. Pollut. Bull. 62, 15961605.

Andrady, A.L., 2015. Persistence of plastic litter in the oceans. In: Bergmann, M., Gutow, L., Klages, M. (Eds.), Marine Anthropogenic Litter. Springer International Publishing, Cham, pp. 57-72.

Barnes, D.K., Galgani, F., Thompson, R.C., Barlaz, M., 2009. Accumulation and fragmentation of plastic debris in global environments. Philos. T. Roy. Soc. B. 364, 1985-1998.

Bejgarn, S., MacLeod, M., Bogdal, C., Breitholtz, M., 2015. Toxicity of leachate from weathering plastics: An exploratory screening study with Nitocra spinipes. Chemosphere 132, 114-119.

Bergami, E., Pugnalini, S., Vannuccini, M. L., Manfra, L., Faleri, C., Savorelli, F., Dawson, K.A., Corsi, I., 2017. Long-term toxicity of surface-charged polystyrene nanoplastics to marine planktonic species Dunaliella tertiolecta and Artemia franciscana. Aquat. Toxicol. 189, 159-169.

Bhattacharya, P., Lin, S., Turner, J. P., Ke, P. C., 2010. Physical adsorption of charged plastic nanoparticles affects algal photosynthesis. J. Phys. Chem. C 114, 16556-16561.

Canesi, L., Balbi, T., Fabbri, R., Salis, A., Damonte, G., Volland, M., Blasco, J., 2017. Biomolecular coronas in invertebrate species: implications in the environmental impact of nanoparticles. Nanolmpact 8, 89-98.

Cole, M., Lindeque, P., Halsband, C., Galloway, T.S., 2011. Microplastics as contaminants in the marine environment: A review. Mar. Pollut. Bull. 62, 2588-2597.

Davarpanah, E., Guilhermino, L., 2015. Single and combined effects of microplastics and copper on the population growth of the marine microalgae Tetraselmis chuii. Estuar. Coast. Shelf Sci. 167, 269-275.

Dawson, A. L., Kawaguchi, S., King, C. K., Townsend, K. A., King, R., Huston, W. M., Bengtson Nash, S. M., 2018. Turning microplastics into nanoplastics through digestive fragmentation by Antarctic krill. Nat. Commun. 9, 1001.

Della Torre, C., Bergami, E., Salvati, A., Faleri, C., Cirino, P., Dawson, K.A., Corsi, I., 2014. Accumulation and embryotoxicity of polystyrene nanoparticles at early stage of development of sea urchin embryos Paracentrotus lividus. Environ. Sci. Technol. 48, 12302-12311.

Dubaish, F., Liebezeit, G., 2013. Suspended microplastics and black carbon particles in the Jade system, southern North Sea. Water Air Soil Pollut. 224, 1352-1359.

Eriksen, M., Lebreton, L.C.M., Carson, H.S., Thiel, M., Moore, C.J., Borerro, J.C., Galgani, F., 
Ryan, P.G., Reisser, J., 2014. Plastic Pollution in the World's Oceans: More than 5 Trillion Plastic Pieces Weighing over 250,000 Tons Afloat at Sea. PLoS One 9, 1-15.

Esperanza, M., Seoane, M., Rioboo, C., Herrero, C., Cid, Á., 2015. Chlamydomonas reinhardtii cells adjust the metabolism to maintain viability in response to atrazine stress. Aquat. Toxicol. 165, 64-72.

Filella, M., 2015. Questions of size and numbers in environmental research on microplastics: methodological and conceptual aspects. Environ. Chem. 12, 527-538.

Foulon, V., Le Roux, F., Lambert, C., Huvet, A., Soudant, P., Paul-Pont, I., 2016. Colonization of polystyrene microparticles by Vibrio crassostreae: Light and electron microscopic investigation. Environ. Sci. Technol. 50, 10988-10996.

Franklin, N.M., Stauber, J.L., Lim, R.P., 2001. Development of flow cytometry-based algal bioassays for assessing toxicity of copper in natural waters. Environ. Toxicol. Chem. 20, 160-170.

Galloway, T. S., Cole, M., Lewis, C., Atkinson, A., and Allen, J. I., 2017. Interactions of microplastic debris throughout the marine ecosystem. Nat. Ecol. Evol. 1, 116.

Gambardella, C., Morgana, S., Bramini, M., Rotini, A., Manfra, L., Migliore, L., Piazza, V., Garaventa, F., Faimali, M., 2018. Ecotoxicological effects of polystyrene microbeads in a battery of marine organisms belonging to different trophic levels. Mar. Environ. Res. $141,313-321$.

Geoffroy, L., Gilbin, R., Simon, O., Floriani, M., Adam, C., Pradines, C., Cournac, L., GarnierLaplace, J., 2007. Effect of selenate on growth and photosynthesis of Chlamydomonas reinhardtii. Aquat. Toxicol. 83, 149-58.

Gigault, J., Halle, A. Ter, Baudrimont, M., Pascal, P. Y., Gauffre, F., Phi, T. L., El Hadri, H., Grassl, B., Reynaud, S., 2018. Current opinion: What is a nanoplastic? Environ. Pollut. 235, 1030-1034.

Gigault, J., Pedrono, B., Maxit, B., Ter Halle, A., 2016. Marine plastic litter: the unanalyzed nano-fraction. Environ. Sci. Nano 3, 346-350.

González-Fernández, C., Tallec, K., Le Goïc, N., Lambert, C., Soudant, P., Huvet, A., Suquet, M., Berchel, M., Paul-Pont, I., 2018. Cellular responses of Pacific oyster (Crassostrea gigas) gametes exposed in vitro to polystyrene nanoparticles. Chemosphere 208, 764772.

Govender, T., Ramanna, L., Rawat, I., Bux, F., 2012. BODIPY staining, an alternative to the Nile Red fluorescence method for the evaluation of intracellular lipids in microalgae. Bioresour. Technol. 114, 507-511.

Hecky, R.E., Mopper, K., Kilham, P., Degens, E.T., 1973. Amino-acid and sugar composition of diatom cell-walls. Mar. Biol. 19, 323-331.

Hermabessiere, L., Dehaut, A., Paul-Pont, I., Lacroix, C., Jezequel, R., Soudant, P., Duflos, G., 2017. Occurrence and effects of plastic additives on marine environments and organisms: a review. Chemosphere 182, 781-793.

Hernandez, L.M., Yousefi, N., Tufenkji, N., 2017. Are there nanoplastics in your personal care products? Environ. Sci. Technol. Lett. 4, 280-285.

Huerlimann, R., Rocky, N., Heimann, K., 2010. Growth, lipid content, productivity and fatty acid composition of tropical microalgae for scale-up production. Biotechnol. Bioeng. $107,245-257$.

Jochem, F. J., 2000. Probing the physiological state of phytoplankton at the single-cell level. 
Sci. Mar. 64, 183-195.

Juneau, P., El Berdey, A., Popovic, R., 2002. PAM fluorometry in the determination of the sensitivity of Chlorella vulgaris, Selenastrum capricornutum and Chlamydomonas reinhardtii to copper. Arch. Environ. Contam. Toxicol. 42, 155-164.

Lambert, S., Wagner, M., 2016. Characterisation of nanoplastics during the degradation of polystyrene. Chemosphere 145, 265-268.

Long, M., Paul-Pont, I., Hégaret, H., Moriceau, B., Lambert, C., Huvet, A., Soudant, P., 2017. Interactions between polystyrene microplastics and marine phytoplankton lead to species-specific hetero-aggregation. Environ. Pollut. 228, 454-463.

Lundqvist, M., Stigler, J., Elia, G., Lynch, I., Cedervall, T., Dawson, K. A., 2008. Nanoparticle size and surface properties determine the protein corona with possible implications for biological impacts. Proc. Natl. Acad. Sci. 105, 14265-14270.

Lusher, A. L., Hollman, P. C. H., Mendoza-Hill, J. J., 2017. Microplastics in Fisheries and Aquaculture: Status of Knowledge on Their Occurrence and Implications for Aquatic Organisms and Food Safety. FAO Fisheries and Aquaculture Technical Paper. No. 615, p. 147.

Maeda, Y., Nojima, D., Yoshino, T., Tanaka, T., 2017. Structure and properties of oil bodies in diatoms. Phil. Trans. R. Soc. 372, 20160408.

Malviya, S., Scalco, E., Audic, S., Vincent, F., Veluchamy, A., Poulain, J., Wincker, P., ludicone, D., de Vargas, C., Bittner, L., Zingone, A., Bowler, C., 2016. Insights into global diatom distribution and diversity in the world's ocean. Proc. Natl. Acad. Sci. 113, E1516E1525.

Mao, Y., Ai, H., Chen, Y., Zhang, Z., Zeng, P., Kang, L., Li, W., Gu, W., He, Q., Li, H., 2018. Phytoplankton response to polystyrene microplastics: Perspective from an entire growth period. Chemosphere 208, 59-68.

Marques-Santos, L. F., Grassi, G., Bergami, E., Faleri, C., Balbi, T., Salis, A., Damonte, G., Canesi, L., Corsi, I., 2018. Cationic polystyrene nanoparticle and the sea urchin immune system: biocorona formation, cell toxicity, and multixenobiotic resistance phenotype. Nanotoxicology 0, 1-21.

Martínez-Gómez, C., León, V. M., Calles, S., Gomáriz-Olcina, M., Vethaak, A. D., 2017. The adverse effects of virgin microplastics on the fertilization and larval development of sea urchins. Mar. Environ. Res. 130, 69-76.

National Oceanic and Atmospheric Administration (NOAA), 2008. Proceedings of the International Research Workshop on the Occurrence, effects, and fate of Microplastic Marine debris. C Arthur, J. Baker, and H. Bamford (eds). NOAA Technical Memorandum NOS-OR\&R-30.

Navarro, E., Baun, A., Behra, R., Hartmann, N.B., Filser, J., Miao, A.J., Quigg, A., Santschi, P.H., Sigg, L., 2008. Environmental behavior and ecotoxicity of engineered nanoparticles to algae, plants, and fungi. Ecotoxicology 17, 372-386.

Nel, A., Xia, T., Mädler, L., Li, N., 2006. Toxic potential of materials at the nano level. Science 311, 622-627.

Nel, A.E., Mädler, L., Velegol, D., Xia, T., Hoek, E.M.V., Somasundaran, P., Klaessig, F., Castranova, V., Thompson, M., 2009. Understanding biophysicochemical interactions at the nano-bio interface. Nat. Mater. 8, 543-557.

Nobre, C. R., Santana, M. F. M., Maluf, A., Cortez, F. S., Cesar, A., Pereira, C. D. S., et al., 2015. 
Assessment of microplastic toxicity to embryonic development of the sea urchin Lytechinus variegatus (Echinodermata: Echinoidea). Mar Pollut. Bull. 92, 99-104.

Nolte, T. M., Hartmann, N. B., Kleijn, J. M., Garnæs, J., van de Meent, D., Jan Hendriks, A., Baun, A., 2017. The toxicity of plastic nanoparticles to green algae as influenced by surface modification, medium hardness and cellular adsorption. Aquat. Toxicol. 183, 11-20.

OECD 201, 2011. Alga Growth Inhibition Test (201). OECD Guideline for Testing of Chemicals. Organization for Economic Cooperation and Development, Paris, France.

Paul-Pont, I., Tallec, K., Gonzalez-Fernandez, C., Lambert, C., Vincent, D., Mazurais, D., Zambonino-Infante, J.L., Brotons, G., Lagarde, F., Fabioux, C., Soudant, P., Huvet, A., 2018. Constraints and priorities for conducting experimental exposures of marine organisms to microplastics. Front. Mar. Sci. 5, 252.

Peeken, I., Primpke, S., Beyer, B., Gütermann, J., Katlein, C., Krumpen, T., Bergmann, M., Hehemann, L., Gerdts, G., 2018. Arctic sea ice is an important temporal sink and means of transport for microplastic. Nat. Commun. 95, 2041-1723.

Pham, C. K., Ramirez-Llodra, E., Alt, C.H.S., Amaro, T., Bergmann, M., Canals, M., Company, J.B., Davies, J., Duineveld, G., Galgani, F., Howell, K.L., Huvenne, V.A., Isidro, E., Jones, D.O., Lastras, G., Morato, T., Gomes-Pereira, J.N., Purser, A., Stewart, H., Tojeira, I., Tubau, X., Van Rooij, D., Tyler, P.A., 2014. Marine litter distribution and density in European seas, from the shelves to deep basins. PLoS ONE 9(4), e95839.

Phuong, N. N., Zalouk-Vergnoux, A., Poirier, L., Kamari, A., Châtel, A., Mouneyrac, C., Lagarde, F., 2016. Is there any consistency between the microplastics found in the field and those used in laboratory experiments? Environ. Pollut. 211, 111-123.

Plastics Europe, 2017. Plastics - the facts 2017. In: An Analysis of European plastics production, demand and waste data. Technical Report.

Prado, R., García, R., Rioboo, C., Herrero, C., Abalde, J., Cid, Á, 2009. Comparison of the sensitivity of different toxicity test endpoints in a microalga exposed to the herbicide paraquat. Environ. Int. 35, 240-247.

Rosenwasser, S., van Creveld, G.S., Schatz, D., Malitsky, S., Tzfadia, O., Aharoni, A., Levin, Y., Gabashvili, A., Feldmesser, E., Vardi, A., 2014. Mapping the diatom redox- sensitive proteome provides insight into response to nitrogen stress in the marine environment. Proc. Natl. Acad. Sci. U. S. A. 111, 2740-2745.

Ruiz-Orejón, L.F., 2016. Floating plastic debris in the central and western mediterranean sea. Mar. Environ. Res. 120, 136-144.

Rumin, J., Bonnefond, H., Saint-Jean, B., Rouxel, C., Sciandra, A., Bernard, O., Cadoret, J.P., Bougaran, G., 2015. The use of fluorescent Nile red and BODIPY for lipid measurement in microalgae. Biotechnol. Biofuels 8, 42.

Ryan, 2015. A Brief History of Marine Litter Research. In: Bergmann, M., Gutow, L., Klages, M. (Eds.), Marine Anthropogenic Litter. Springer International Publishing, pp. 1-25.

Ryan, P.G., Moore, C.J., van Franeker, J.A., Moloney, C.L., 2009. Monitoring the abundance of plastic debris in the marine environment. Philos. Trans. R. Soc. B 364, 1999-2012.

Sanka, I., Suyono, E.A., Alam, P., 2017. The effects of diatom pore-size on the structures and extensibilities of single mucilage molecules. Carbohydr. Res. 448, 35-42.

Seoane, M., Esperanza, M., Cid, Á., 2017a. Cytotoxic effects of the proton pump inhibitor omeprazole on the non-target marine microalga Tetraselmis suecica. Aquat. Toxicol. 
$191,62-72$.

Seoane, M., Esperanza, M., Rioboo, C., Herrero, C., Cid, Á., 2017b. Flow cytometric assay to assess short-term effects of personal care products on the marine microalga Tetraselmis suecica. Chemosphere, 171, 339-347.

Sjollema, S.B., Redondo-Hasselerharm, P., Leslie, H. a., Kraak, M.H.S., Vethaak, a. D., 2016. Do plastic particles affect microalgal photosynthesis and growth? Aquat. Toxicol. 170, 259-261.

Sun, X., Chen, B., Li, Q., Liu, N., Xia, B., Zhu, L., Qu, K., 2018. Toxicities of polystyrene nanoand microplastics toward marine bacterium Halomonas alkaliphila. Sci. Total Environ. $642,1378-1385$.

Tallec, K., Huvet, A., Di Poi, C., González-Fernández, C., Lambert, C., Petton, B., Le Goïc, N., Berchel, M., Soudant, P., Paul-Pont, I., 2018. Nanoplastics impaired oyster free living stages, gametes and embryos. Environ. Pollut. 242, 1226-1235.

Ter Halle, A., Jeanneau, L., Martignac, M., Jardé, E., Pedrono, B., Brach, L., Gigault, J., 2017. Nanoplastic in the North Atlantic Subtropical Gyre. Environ. Sci. Technol. 51, 1368913697.

Verma, A., Stellacci, F., 2010. Effect of surface properties on nanoparticle-cell interactions. Small 6, 12-21.

Von Moos, N., Burkhardt-Holm, P., Köhler, A., 2012. Uptake and effects of microplastics on cells and tissue of the blue mussel Mytilus edulis L. after an experimental exposure. Environ. Sci. Technol. 46, 11327-11335.

Walne, P. R., 1966. Experiments in the Large-scale Culture of the Larvae of Ostrea edulis L. Fishery In, Her Majesty's Stationery Office, London.

Wolff, C., Fuks, B., Chatelain, P., 2003. Comparative study of membrane potential- sensitive fluorescent probes and their use in ion channel screening assays. J. Biomol. Screen 8 , 533-543.

Xu, Z.B., Yan, X.J., Pei, L.Q., Luo, Q.J., Xu, J.L., 2008. Changes in fatty acids and sterols during batch growth of Pavlova viridis in photobioreactor. J. Appl. Phycol. 20, 237-243.

Yin, L., Chen, B., Xia, B., Shi, X., Qu, K., 2018. Polystyrene microplastics alter the behavior, energy reserve and nutritional composition of marine jacopever (Sebastes schlegelii). J. Hazard. Mater. 360, 97-105.

Yokota, K., Waterfield, H., Hastings, C., Davidson, E., Kwietniewski, E., Wells, B., 2017. Finding the missing piece of the aquatic plastic pollution puzzle: Interaction between primary producers and microplastics. Limnol. Oceanogr. Lett. 2, 91-104.

Yusko, E.C., Asbury, C.L., 2014. Force is a signal that cells cannot ignore. Mol. Biol. Cell 25, 3717-3725.

Zhang, C., Chen, X., Wang, J., Tan, L., 2017. Toxic effects of microplastic on marine microalgae Skeletonema costatum: interactions between microplastic and algae. Environ. Poll. 220, 1282-1288.

Zienkiewicz, K., Du, Z. Y., Ma, W., Vollheyde, K., Benning, C., 2016. Stress-induced neutral lipid biosynthesis in microalgae - Molecular, cellular and physiological insights. Biochim. Biophys. Acta 1861, 1269-1281. 
Table 1. Characterization of PS- $\mathrm{NH}_{2} \mathrm{MP}$ in Milli $\mathrm{Q}$ water, filtered natural seawater (FSW) and microalgae medium using DLS analysis. Z-average (nm),

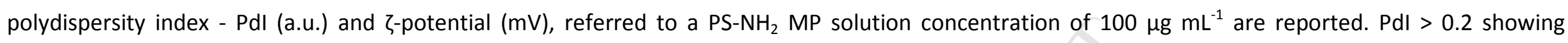
aggregation is marked by an asterisk $(*)$. Values are shown as mean \pm standard deviation of the three measurements.

\begin{tabular}{|c|c|c|c|c|c|c|c|c|c|}
\hline \multirow[b]{2}{*}{$\begin{array}{l}\text { Nominal } \\
\text { size }\end{array}$} & \multicolumn{3}{|c|}{ Milli Q } & \multicolumn{3}{|c|}{ FSW } & \multicolumn{3}{|c|}{ Filtered $(0.2 \mu \mathrm{m})$ microalgal culture medium } \\
\hline & $\begin{array}{c}\text { Size } \\
\text { Z-average }(\mathrm{nm})\end{array}$ & $\begin{array}{l}\text { Pdl } \\
\text { (a.u.) }\end{array}$ & $\begin{array}{c}\text { Charge } \\
\zeta \text {-potential (mV) }\end{array}$ & $\begin{array}{c}\text { Size } \\
\text { Z-average }(\mathrm{nm})\end{array}$ & $\begin{array}{l}\text { Pdl } \\
\text { (a.u.) }\end{array}$ & $\begin{array}{c}\text { Charge } \\
\text { 万-potential (mV) }\end{array}$ & $\begin{array}{c}\text { Size } \\
\text { Z-average }(\mathrm{nm})\end{array}$ & $\begin{array}{l}\text { Pdl } \\
\text { (a.u.) }\end{array}$ & $\begin{array}{c}\text { Charge } \\
\zeta \text {-potential (mV) }\end{array}$ \\
\hline $0.5 \mu \mathrm{m}$ & $602.5 \pm 27.3$ & $0.16 \pm 0.02$ & $-11.9 \pm 0.6$ & $2899.0 \pm 96.0$ & $0.46 \pm 0.10^{*}$ & $-7.3 \pm 0.9$ & $3268.0 \pm 64.3$ & $0.40 \pm 0.02 *$ & $-6.9 \pm 1.7$ \\
\hline $2 \mu \mathrm{m}$ & $2274.0 \pm 100.9$ & $0.16 \pm 0.08$ & $-12.8 \pm 0.3$ & $5932.0 \pm 694.4$ & $0.89 \pm 0.10 *$ & $-4.8 \pm 0.5$ & $4342.3 \pm 294.2$ & $0.67 \pm 0.15^{*}$ & $-5.0 \pm 2.0$ \\
\hline
\end{tabular}




\section{ACCEPTED MANUSCRIPT}

Table 2. Growth rates $\mu\left(\right.$ day $^{-1}$ ) of $C$. neogracile cultures exposed to 0 and $2.5 \mu \mathrm{g} \mathrm{mL}^{-1}$ of $0.5 \mu \mathrm{m}$ and $2 \mu \mathrm{m}$ PS $-\mathrm{NH}_{2}$ MP at each sample time. Data are given as mean values \pm standard deviation of three replicates. Significant differences with respect to control at a level of significance of $0.05(p<0.05)$ are represented by an asterisk $(*)$.

\begin{tabular}{cccc} 
& \multicolumn{3}{c}{ Growth rate $\boldsymbol{\mu}\left(\right.$ day $\left.^{-1}\right)$} \\
\hline Particle type & $\mathbf{2 4} \mathbf{~}$ & $\mathbf{4 8 ~ h}$ & $\mathbf{7 2 ~ \mathbf { ~ }}$ \\
\hline Control & $1.56 \pm 0.06$ & $1.59 \pm 0.05$ & $1.44 \pm 0.02$ \\
$\mathbf{0 . 5} \boldsymbol{\mu m}$ & $1.63 \pm 0.02$ & $1.58 \pm 0.02$ & $1.44 \pm 0.01$ \\
$\mathbf{2} \boldsymbol{\mu m}$ & $1.61 \pm 0.09$ & $1.55 \pm 0.03$ & $1.39 \pm 0.01^{*}$
\end{tabular}



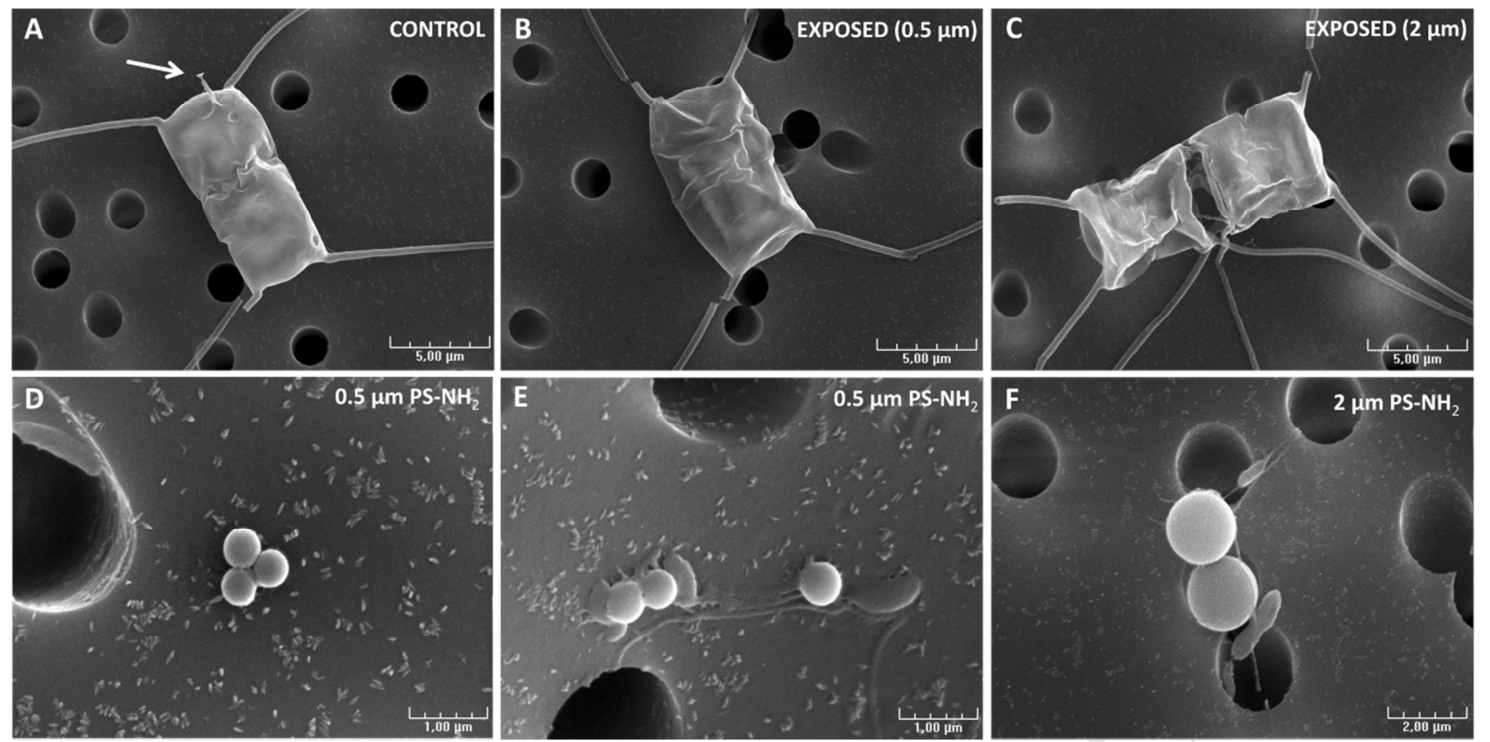

Figure 1. Scanning electron micrographs showing a control cell (A) and cells exposed to $0.5 \mu \mathrm{m}$ (B) and $2 \mu \mathrm{m}$ PS-NH $\mathrm{NH}_{2} \mathrm{MP}(\mathbf{C}) .0 .5 \mu \mathrm{m}$ (D, E) and $2 \mu \mathrm{m}$ (F) PS-NH $\mathrm{NH}_{2}$ beads micro-aggregates and bacteria are also shown. Arrow indicates a rimoportula (tubular process through the valve of some diatoms). Scale bars: $5 \mu \mathrm{m}(\mathrm{A}, \mathrm{B}, \mathrm{C}) ; 1 \mu \mathrm{m}(\mathrm{D}, \mathrm{E}) ; 2 \mu \mathrm{m}(\mathrm{F})$. 

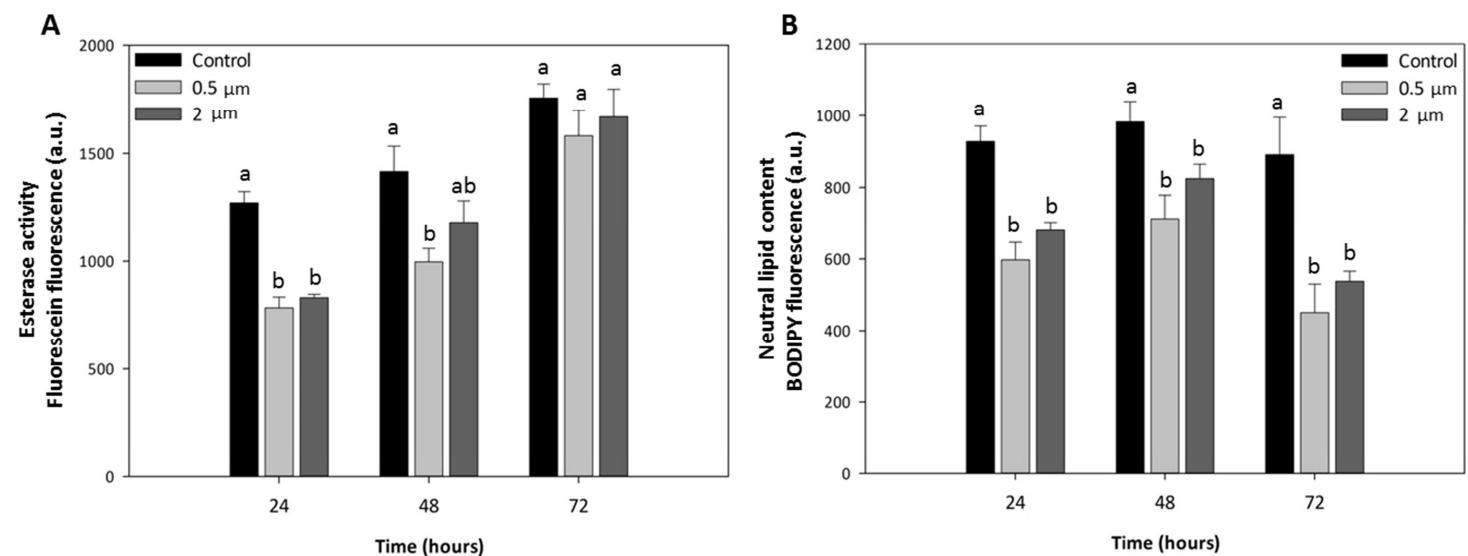

Figure 2. Esterase activity (A) and neutral lipid content (B) of C. neogracile cells in control cultures and cultures exposed to $2.5 \mu \mathrm{g} \mathrm{mL}^{-1}$ of 0.5 and $2 \mu \mathrm{m}$ PS-NH $\mathrm{N}_{2} \mathrm{MP}$ for 24,48 and $72 \mathrm{~h}$. Significant differences between treatments are marked with lowercase letters $(p<0.05)$. 


\section{Highlights}

1. Effects of 0.5 and $2 \mu \mathrm{m}$ PS- $\mathrm{NH}_{2}$ microplastics (MP) were evaluated on $\mathrm{C}$. neogracile

2. MP showed negative charge, were aggregated and were not attached to the cell wall

3. Exposure to MP decreased the cellular metabolic activity and neutral lipid content

4. Cells modulate their energy metabolism to properly acclimate to the stress conditions

5. Microalgal oil bodies serve as an energy source for maintaining a healthy status 